121.

\section{Medical Tasks, Planning and Logistics of United Nation's Protection Forces (UNPROFOR) in the Former Yugoslavia}

Knut Ole Sundnes, MD, Lt. Colonel

UNPROFOR Headquarters, Zagreb, Croatia

UNPROFOR, as of 30 January 1995, so far is the United Nation's (UN) largest and most complex peace-keeping operation. It is comprised of 44,246 persons in three commands: Croatia, Bosnia and Herzegovina, and the former Yugoslavian Republic of Macedonia. The UN peacekeepers face problems different from other humanitarian relief organizations, trying both to monitor and control the conflict. UNPROFOR assists in the distribution of medical supplies, treatment of locals, displaced persons, and refugees, and with the medical evacuation of civilians in coordination with UNHCR, IOM and ICRC. It improves public health by providing engineering support to refugee camps and communities. Medical treatment is provided where the health infrastructure is insufficient. The total number of civilians treated is very high. The provision of medical supplies earmarked for civilians is tasked to UNHCR, WHO, ICRC, and other organizations. The medical system in UNPROFOR is designed to support all UN troops and has a considerable capacity. Two 60-bed hospitals, 29 field surgical teams, and 31 battalion aid stations comprising 1,277 medical personnel (206 MDs) cover most of the medical needs. Of the 1,322 UN casualties sustained so far in the former Yugoslavia, $41 \%$ were war-related ( $36 \%$ from mines, $32.5 \%$ from shelling, and $31.5 \%$ related to direct firing); $30 \%$ were related to traffic accidents.

So far, UNPROFOR has suffered 137 deaths. Multi-casualty incidents are uncommon. In special situations, civilian hospitals support UNPROFOR. Lack of respect for the Geneva Conventions often has hindered the provision of adequate medical supplies and the medical evacuation of UN troops and civilians. Logistical and operational planning covers all contingencies from total withdrawal to enhancement of efforts.

\section{1.}

\section{Terrorist Attack to the AMIA (Jewish Mutual Society of Argentina) Headquarters Building}

Dr. Alberto Crescenti, Dr. Jose G. Filet Cerviño, Dr. Omar Isse, Dr. Vicente Carluccio, Dr. Humberto Sanguinetti

Buenos Aires, Argentine

This presentation outlines the response by the Emergency Medical Response System of the Municipality of Buenos Aires to a terrorist attack to the AMIA Headquarters that resulted in 100 people dead and 206 people injured. The city of Buenos Aires, capital of Argentine Republic, in South America, has a stable population of 3 million inhabitants and 4 million transient people during working days. On 18 July 1994, at 09:53 hours, a bomb exploded in the AMIA building, located in a commercial zone that is thickly populated. This resulted in mass casualties and material destruction.
Response: Activation of the Medical Disaster and Catastrophe Plan for the City of Buenos Aires.

Description: Command post, noria, casualties evacuation, assistance to trapped victims.

050.

Victims of the Palestinian Uprising (Intifada): A Retrospective Review of $\mathbf{2 2 0}$ Cases

Hashmonai Derazon, MD, Emile Hay, MD

Barzilai Medical Center, Ashkelon, Israel

The Barzilai Medical Center is located $20 \mathrm{~km}$ from Gaza. It is a level-II trauma center and is the nearest Israeli referral receiving medical center for injured citizens and soldiers from the Gaza area. During the period of April 1993 to April 1994, 220 victims of the Palestinian Uprising (Intifada) were referred to this medical center. Of these, 41 of the patients $(18.6 \%)$ were citizens of the Gaza area; $26(11.8 \%)$ were Israeli citizens; and $153(69.6 \%)$ were Israeli soldiers. Five patients were under the age of 17 years; two were women; and the rest were men. Two Israeli citizens died at the scene, and two Gaza citizens died in the emergency department. Fifty-five patients (25.\%) were injured by firearms; 10 patients $(4.5 \%)$ by explosives; 120 $(54.5 \%)$ by striking stones and other objects; $14(6.4 \%)$ by knives and sharp objects; four $(1.8 \%)$ by shrapnel; and 17 $(7.8 \%)$ by other means. Seventy-three of the victims $(33.2 \%)$ were hospitalized; 22 patients $(10 \%)$ needed surgery. Four patients $(1.8 \%)$ were transferred to a level-I trauma center. Emergency thoracotomy was performed on one patient for a stab-wound injury to the heart. The body parts injured in declining incidence were: extremities $(41.4 \%)$, head and neck . $(38.6 \%)$, chest $(6.4 \%)$, and abdomen $(1.4 \%)$. Twenty-seven patients $(12.2 \%)$ had multiple sites of injuries. The total expenses for patients treated in the emergency department were 25,343 NIS. A total of 345 hospitalization days was recorded with total expenses amounting to 320,000 NIS. The Palestinian Uprising resulted in a high cost in teerms of lives lost and actual expenses to both nations.

\section{2.}

\section{Mass Casualty Incidents In Israel: 21 Incidents Treated by Magen Davld Adom in 1993-1994}

\section{Z. Feigenberg, $M D$}

Medical Director, Magen David Adom in Israel, Tel Aviv, Israel

Twenty-one multi-casualty events averaging 35 casualties per event were treated by Magen David Adom (MDA) teams in 1993-1994. Twelve of these events were serious road accidents, five fires, three bombings (Afula, Hadera, Tel Aviv), and one was caused by dangerous materials. Compilation and analysis of statistics on the scope of events and activity of MDA teams involved, enabled MDA to construct a model of its response ability, determine whether its treatment principles withstood 
the test of reality, and find weak points requiring improvement. Principal data compiled are as follows: nine standard ambulances, two Mobile Intensive Care Units, 26 rescuers (staff and volunteers). MDA Region Managers served as incident commanders in 14 incidents, and paramedics in the remaining seven.

\section{Average timetable for incidents covered:}

Time to arrival of first ambulance:

Time to assembly of entire team:

Time from arrival to first evacuation:

Average evacuation time to hospital:

Completion of treatment and evacuation:

\author{
7.5 minutes. \\ 29.5 minutes. \\ 7 minutes. \\ 1.5 minutes \\ 44 minutes from call.
}

Distribution of casualty evacuation:

$\begin{array}{cc}\text { No. of Hospitals } & \text { No. of Events } \\ 4 & 3 \\ 3 & 5 \\ 2 & 3 \\ 1 & 7\end{array}$

The vast differences in cause, location, and type severity of casualties mean that this model understanding of MDA activity of events, number and enables better overall preparedness in future.

\section{7.}

\section{Terrorism and Heroism: The Bombing of the World Trade Center-An Inside Look at the Emergency Medical Response}

\author{
Steven Kuhr, CEM, EMT-Paramedic, \\ Chief Zachary Goldfarb, AS, EMT-Paramedic \\ New York City Emergency Medical Services, New York, \\ New York USA
}

Incident Overview: The bombing of the World Trade Center
occurred on a work day at 12:18 hours on 26 February 1993 .
The complex of seven commercial, high-rise buildings, was
fully occupied and contained approximately 150,000 people.
The bombing resulted in a fire, major subterranean structural
collapse of all five levels of the parking garage and the lobby of
the Vista Hotel, and resulted in 1,042 patients.
Objective: The response and operation will be explored in an
effort to illustrate the details of a major medical and rescue dis-
aster and to share key operational points and lessons learned.
The goal is to demonstrate the need for major disaster plan-
ning within the medical community.
1) New York City medical disaster management program,
Incident Command System, and World Trade Center
preplanning;
2) Below ground obstacles and rescue;
3) Evacuation of those trapped in the towers;
4) Medical command and control, mutual aid, triage, casualty
collection/victim treatment, and hospital deployment; and
5) Continued 9-1-1 service to the unaffected community, and
major mutual-aid.
Summary: This incident officially brought terrorism to the
United States. America no longer can feel safe with an attitude that "it will never happen here"....it has. This attitude must be shared with and felt by the world community. It is incumbent directly upon the emergency and medical community to plan ahead to ensure that they are at their fullest capacity to confront major disasters.

103.

\section{Disaster Victim Identification following Tel Aviv Bombing}

Dr. Jay Levinson

Disaster Victim Identification Officer, Israel Police National

Headquarters, Jerusalem, Israel

Disaster Victim Identification is a multi-faceted operation that must be well-coordinated. Following the 19 October 1994 bomb explosion aboard a Tel Aviv bus, an information bureau was established as a result of cooperation between the Israel Police and the Tel Aviv Municipality. As soon as names of hospitalized victims were established, they were made known to the Information Bureau and to DVI personnel in the Institute of Forensic Medicine which served as the morgue for the operation. Persons calling the Information Bureau were directed either to hospital Personal/Missing Persons Unit located in a building 100 meters from the morgue. There, information was collected concerning missing persons, usually with the aid of a psychologist or social worker, and always with a doctor present. Then the information (AM) was compared with Post Mortem (PM) data recorded by DVI teams. Receipt of accurate lists of hospitalized persons speeded the DVI task by reducing the number of missing persons. Information about missing body parts of survivors was also transferred to the Morgue to help in accounting for all material recovered.

\section{9.}

\section{Looking Back on the Amia Outrage}

Marcelo Muro, MD, Analia Fuentes, MD, Claudio Waisbord, Luis Pesce

Vittal Emergency Medical Services, Buenos Aires, Argentine

Two years after the explosive attempt to the Embassy of Israel, 18 July at 09:56 hours, Buenos Aires was shocked again. The Jewish Mutual in Argentina (Amia) building was demolished by a new explosion. Vittal E.M.S. is one of the biggest systems in Buenos Aires and seven ambulances were sent to the scene. They arrived at the scene from different points in the city within 15 minutes. This is our report of that cruel event.

One of us was a few meters away from where the bomb went off. The scene was one of desolation. We gathered four bodies and two lines of volunteers formed on the heap of rubble. Everyone did what they could, often in a disorderdly manner and running unnecessary risks. The first hand-held megaphones arrived at 11:00 hours. Later, when we met our colleagues, we were summoned to the library where we found 